\title{
Research on Bilingual Teaching Effect of International Trade Major in Local Universities Based on Student Feedback
}

\author{
Min Zheng*, Dengcheng Ma \\ School of Logistics, Linyi University, Linyi, China \\ Email: *xiaojun728@163.com
}

How to cite this paper: Zheng, M., \& Ma, D. C. (2021). Research on Bilingual Teaching Effect of International Trade Major in Local Universities Based on Student Feedback. Creative Education, 12, 2928-2933. https://doi.org/10.4236/ce.2021.1212219

Received: November 10, 2021

Accepted: December 25, 2021

Published: December 28, 2021

Copyright ( 2021 by author(s) and Scientific Research Publishing Inc. This work is licensed under the Creative Commons Attribution International License (CC BY 4.0).

http://creativecommons.org/licenses/by/4.0/

\section{(c) (i) Open Access}

\begin{abstract}
How to carry out bilingual teaching among undergraduates majoring in international trade is still a new topic in undergraduate teaching of international trade. Bilingual teaching in undergraduate business negotiation courses has been carried out for four consecutive years. The students participating in bilingual learning involve sophomores and third graders of the Business School of Linyi University. At the beginning and end of bilingual teaching, questionnaires and symposiums on bilingual teaching were conducted for each class of students. At the same time, a follow-up survey of bilingual teaching was conducted for former students who had studied bilingual. According to the problems reflected in the questionnaire, all links of teaching should be improved, so that bilingual teaching is accepted by more and more students. It is believed that the objectives, teaching methods and evaluation indicators of bilingual teaching should be different according to different student groups and different curriculum properties.
\end{abstract}

\section{Keywords}

Questionnaire Survey, Bilingual Teaching, Teaching Objectives, Evaluating Indicator

\section{Introduction}

According to the spirit of the outline of the national medium and long term education reform and development plan (2010-2020) released by the Ministry of education on July 29,2010, bilingual courses on business negotiation for students majoring in international economy and trade has been started since 2010 . Since the establishment of the school level teaching reform project in 2018, we have continuously tracked and investigated the bilingual teaching practice and 
feedback (Shi \& Cong, 2021). The students participating in bilingual learning involve 400 students majoring in international economics and trade in the Business School of Linyi University, all of whom are sophomores and junior students. There are two ways to set up bilingual classes: undergraduate class and junior college to this class. Two versions of English textbooks have been used. The keynote teachers engaged in bilingual teaching have many years of experience in learning and living in native English speaking countries, and the young teaching assistants have also received high-level oral English training. In teaching, the advantages of Chinese and Western teaching ideas are organically integrated. Adopt various forms of teaching methods and flexible assessment methods to stimulate students' interest in learning. Pay attention to the cultivation of the basic quality of undergraduate scientific research. At the same time, it has also built a rich video case library, compiled auxiliary teaching materials, built school-level first-class courses, and established a multi-channel teaching feedback system. In the process of teaching, the principles of active investment is followed, step by step, practical and pragmatic, and strive for a win-win situation in English and professional courses (Yang \& Che, 2020). The following summarizes students' feedback in several aspects, analyzes the problems reflected and puts forward improvement suggestions.

\section{On the Suitable Student Groups, Class Types, Timing and Objectives of Bilingual Teaching and the Requirements for Teachers' Quality}

Bilingual teaching class is divided into undergraduate class and upgraded class. The undergraduate students have a good foundation in English. Most of them have passed CET- 4 when they accept bilingual courses. The students in the upgraded class have the enthusiasm to learn bilingual courses, but the foundation of English is not very good. Both classes use English books, English homework and exams, but the rate of teachers using English in class is decreasing. The subject teaching objectives are basically the same. The teaching objectives are different: for the undergraduate class, students are required to be able to conduct business negotiations in English, while for the upgraded class, students are only required to do simple English case analysis ppt. For the best time to start bilingual courses, $58.2 \%$ of the students think grade one and grade two are good for two reasons: 1) the basic courses in grade one and grade two are easy to learn and have more time to study. 2) It can lay a foundation for bilingual and even all English Teaching of professional courses set up in senior grades. $41.8 \%$ of the students believe that the senior year is better, which is conducive to direct understanding and contact with the forefront of the major, and is conducive to the integration of professional courses with international standards. In the follow-up survey of previous students, all students who recognize bilingual teaching without exception believe that it is best to have bilingual courses in four years of University. Therefore, in the long run, bilingual teaching should form a hori- 
zontal and vertical curriculum system to ensure the sustainability of bilingual teaching effect. From the questionnaire, feedback and assessment results, the class type with the best bilingual learning effect is the undergraduate class. From the individual point of view, the bilingual learning effect of those students whose study hard is also very good. $71.1 \%$ think that bilingual learning will increase the learning burden, while only $28.3 \%$ think not. Therefore, we believe that in general, for students with high learning foundation and character quality, the goal of bilingual teaching (including professional knowledge and language ability) can be set higher, and the number of classes should not be too large (no more than 40 people). For students with general learning foundation and character quality, the language teaching goal in bilingual teaching should be to lay the foundation for bilingual learning in the future (Amini et al., 2014). The results of the survey show that $86.5 \%$ of the students expressed their willingness to participate in bilingual learning. $4.3 \%$ of the students expressed their resistance and disapproval of bilingual teaching, while others said it didn't matter. However, the follow-up survey of previous students shows that this proportion is much higher than that of the current year. It shows that with the increase of learning experience, the demand and recognition of bilingual teaching have also increased. Students who are resistant to bilingual teaching generally have a poor English foundation, and can't keep up with the progress because they don't get the timely help of teachers, resulting in fear and even resistance. It can be seen that the role of teachers in bilingual learning is greater than that of students in Chinese learning (Chen, 2012). The survey shows that $52.1 \%$ of junior students have no habit of taking notes and reading extracurricular reference books. This requires junior bilingual teachers not only to have rich teaching experience in this subject, but also to spend more energy to help students establish good college learning habits. For this reason, $70 \%$ of the students hope that bilingual classes will be taught by Chinese teachers with good English, so as to facilitate communication with teachers. The Classification of questions is showing in Table 1.

Table 1. Classification of questions of questionnaire.

\begin{tabular}{|c|c|c|c|c|c|}
\hline Problem aspect & Title content & $\begin{array}{l}\text { Corresponding } \\
\text { question number }\end{array}$ & Problem aspect & Title content & $\begin{array}{l}\text { Corresponding } \\
\text { question number }\end{array}$ \\
\hline \multirow{3}{*}{$\begin{array}{l}\text { Student } \\
\text { situation }\end{array}$} & English lever & 1 & \multirow[b]{2}{*}{ Teacher ability } & English \& Major & 6,8 \\
\hline & $\begin{array}{l}\text { Learning purpose } \\
\text { \& Attitude }\end{array}$ & $2,10-12$ & & Teaching skills & 13 \\
\hline & Pre-bilingual course & 3 & Curriculum and teaching & English proportion & 5 \\
\hline \multirow{3}{*}{ Teaching effect } & Acceptance \& Satisfaction & 4,15 & & Textbook selection & 7 \\
\hline & Influence factor & 6 & & $\begin{array}{c}\text { Teaching } \\
\text { \& Assessment }\end{array}$ & 8,9 \\
\hline & $\begin{array}{l}\text { Learning difficulties } \\
\text { \& Evaluation }\end{array}$ & 13,14 & & Preview \& Review & $10-12$ \\
\hline
\end{tabular}




\section{On Bilingual Teaching Methods and Assessment Methods}

The teaching feedback questionnaire shows that students believe that the effect of bilingual teaching depends on $41.2 \%$ of teaching methods and means, $36.3 \%$ on students and $22.5 \%$ on teachers. Therefore, in-depth research on foreign teaching has been conducted, tried our best to maintain the advantages of Western teaching ideas embodied in the original teaching materials, improved the traditional teaching methods, increased video case base, simulated negotiation, writing course papers and other methods, and stimulated our learning enthusiasm. In the assessment, increase the diversity of usual assessment and the weight in the final grade, and encourage students to overcome the double difficulties of specialty and language learning and actively participate in teaching. In the questionnaire survey, an average of $82.9 \%$ of students prefer a variety of teaching methods in bilingual courses. It is considered that these teaching methods are helpful to cultivate the ability to ask and think about problems, the ability to find and read relevant materials and summarize, the ability of cooperation and communication, the ability of effective self-expression, and the expansion and extension of knowledge (Liu, 2009). In the follow-up survey of previous students, $72.1 \%$ of the students thought that these abilities were very helpful to the learning of senior students and future research. This proportion is higher among students who study better. In addition, $75 \%$ of students prefer the writing style of English textbooks: vivid, shallow in deep out, close to reality. When bilingual teachers generally believe that bilingual courses should be increased, $46 \%$ of the students think it is unnecessary and think that students need to understand no matter how much teachers talk. These show the necessity of improving traditional teaching methods.

On the issue of the proportion of English application in each link of bilingual teaching, most students agree with the proportion of English application in teaching materials, exercises, examinations and other links. However, there are great differences in the proportion of foreign language teaching in the classroom. $36 \%$ think the proportion should be about $30 \%$; $42 \%$ for $50 \%-70 \% ; 2 \%$ for $100 \%$ English teaching; $20 \%$ shall be determined according to the content. It can be seen that students have recognized and expressed their needs for the use of English in classroom teaching. But teaching in English is not acceptable. The students have given great recognition to our current diversified assessment methods to strengthen the weight of usual performance. At the same time, $34 \%$ of students believe that their usual grades should be increased to $50 \%$, because participating in diversified teaching methods takes up a lot of energy. $70 \%$ of the students believe that the effect of bilingual teaching should mainly depend on students' satisfaction and help for future learning. The questionnaire survey before starting the bilingual course shows that all students who express their willingness to participate in bilingual learning hope that through the bilingual course, they can not only learn professional course knowledge, improve their English level, but also see foreign teaching and broaden their horizons. The 
questionnaire survey after bilingual learning shows that $64 \%$ of students are very satisfied with bilingual teaching, $32 \%$ are basically satisfied, and $4 \%$ think it is difficult to evaluate.

\section{On Bilingual Teaching Resources and Learning Environment}

The construction of bilingual teaching resources includes the training of bilingual teachers, the selected English teaching materials, tracking and making use of high-quality teaching resources at home and abroad, making full and effective use of information-based teaching facilities and technologies, and strengthening the application of information-based teaching among team members. The construction of bilingual teaching environment includes the number and types of English bibliographies in the library, English video resources related to the course, direct contact with foreign universities and the cooperation of Public English courses, etc. (Jia \& Jing, 2020). 82.3\% of the students thought that the types of English reference books in the school were good, but the number was far from enough, and there was no corresponding exercise book. To this end, we have built a rich video case base, planned to strengthen the construction and application of SPOC platform, update and enrich multimedia teaching courseware, and establish an online automatic evaluation system to make the course teaching process traceable and measurable. This is not only conducive to students' after-school learning, but also convenient for the communication between teachers and students. $85.1 \%$ of the students think these are very helpful to bilingual learning. However, $24.9 \%$ of students can not make timely use of online resources. As for bilingual teaching materials, the questionnaire survey shows that $67.4 \%$ of the students think that the narrative problems of English teaching materials are easy to understand, that is, they often explain difficult problems in the form of simple case analysis, which is easy to understand and accept. The knowledge points of Chinese textbooks are clear and systematic, which is conducive to review. When asked whether it was unnecessary to read Chinese reference books, $85 \%$ of the students thought it was necessary. Especially in the early stage of bilingual learning, $72.3 \%$ of students believe that appropriate assessment methods should be used to supervise and encourage students' reading of English books. It can be seen that students use and rely on English and Chinese textbooks differently in different periods of bilingual learning (Freel et al., 2011).

\section{Conclusion}

Bilingual teaching is a systematic project. Bilingual teaching needs to see the long-term effect (Wang et al., 2020). Many senior students wrote in the follow-up survey: "I have only realized the cultivation of my English practical application ability by the bilingual course at that time until now." Although Linyi university has carried out bilingual teaching for the business negotiation course for students majoring in international economy and trade since 2010, about the signi- 
ficance of bilingual teaching, teaching methods, means, objectives and assessment methods. Evaluation indicators have always been different. Exploration and practice with a scientific attitude must be adhered to so as to combine teaching research with practice, promote each other and constantly improve. The object of bilingual teaching is students. From the questionnaire survey and feedback of bilingual teaching for students, the success and existing problems of bilingual teaching can be seen. The summary of these achievements and the analysis of existing problems reflect the common things in bilingual teaching, which is of great benefit to improve the effect of bilingual teaching in the future.

\section{Funding}

This work is supported by Teaching Reform and Research Project of Linyi University 2018.

\section{Conflicts of Interest}

The authors declare no conflicts of interest regarding the publication of this paper.

\section{References}

Amini, M. I., Takmil, F. R., Abiri, S. A. et al. (2014). The Use of the Dundee Three-Cicle Model to Assess Quality of Medical Education. Medical Teacher, 1, 159-171.

Chen, X. (2012). The Measure Analysis of Promoting Bilingual Teaching Effect. Proceedings of 2012 International Symposium-Educational Research and Educational Technology. Plum-Blossom Press, 527-531.

Freel, B., Clark, M., Anderson, M., Gilbert, G., Musyoka, M., \& Hauser, P. (2011). Deaf Individuals' Bilingual Abilities: American Sign Language Proficiency, Reading Skills, and Family Characteristics. Psychology, 2, 18-23. https://doi.org/10.4236/psych.2011.21003

Jia, H., \& Jing, Y. (2020). Study on the Bilingual Teaching of International EconomicsBased on the Model of Outcome-Based Education. Creative Education, 11, 1407-1417. https://doi.org/10.4236/ce.2020.118103

Liu, Y. (2009). On the Improvement of Blingual Teaching Effect-Taking Microeconomics Teaching as an Example. Journal of Sichuan Institute of Education, 6, 87-90.

Shi, Q., \& Cong, Z. (2021). Research on Bilingual Teaching Effect and Quality Assurance Mechanism. Science, Education and Culture Collection, 1, 4-7.

Wang, J., Chen, G., \& Li, B. (2020). From the Perspective of Blended Teaching: The Application of Fragmented Learning in the Class of Bilingual Teaching. Creative Education, 11, 2213-2217. https://doi.org/10.4236/ce.2020.1111161

Yang, R., \& Che, T. (2020). Mechanism Analysis of Microeconomic Bilingual Teaching to Improve Learning Effect Based on Text Analysis. Education and Teaching Forum, 47, 134-136. 